\title{
MJN \\ EFFECT OF AN EDUCATIONAL SUPPORTIVE PROGRAM ON SELF-ESTEEM AND MARITAL RELATION AMONG WOMEN UNDERGOING HYSTERECTOMY
}

\author{
Rania EidFarrag ${ }^{1}$, Reda M. Nabil Aboushady $^{2}$, Helalia Shalabi Mohamed ${ }^{3}$ \\ ${ }^{1}$ Maternal and Newborn Health Nursing, Faculty of Nursing, Fayoum University, Egypt \\ ${ }^{2}$ Maternal and Newborn Health Nursing, Faculty of Nursing, Cairo University, Egypt \\ ${ }^{3}$ Community Health Nursing, Faculty of Nursing, Cairo University, Egypt \\ *Corresponding Author's Email: redaaboushady.77@gmail.com
}

\begin{abstract}
Background: Hysterectomy is the surgical removal of the uterus. It may also involve the removal of the cervix, ovaries, fallopian tubes and other surrounding structures. It is the second commonest surgical operation experienced by women worldwide that associated with low self-esteem and sexual dysfunction. Aim: The aim of the current study was to study the effect of an educational-supportive program on selfesteem and marital relation among women undergoing hysterectomy. Methods: A quasi-experimental one group Pretest-posttest design was adopted in this study. Setting: This study was conducted in the Gynecological outpatient clinic at Fayoum University hospital, Egypt. Subjects: A total of 60 women who had undergone hysterectomy and their husbands who accompanied them were included in this study. Tools: Five tools were used to collect pertinent data: I. Women structured interviewing questionnaire, II. Health Assessment questionnaire. III. The Rosenberg Self-Esteem Scale, IV. Marital Relation Questionnaire, and V. Spousal Support Scale. Results: The mean age was $42.8 \pm 11.3$ years for women and $47.3 \pm 9.4$ years for their husband. The main reason for undergoing hysterectomy was bleeding $(53.3 \%)$, followed by fibroid (18.3\%), and uterine prolapse (15\%). The level of self-esteem and marital relation were also improved after the intervention (one month and three months later) with statistically significant differences. Conclusion: self-esteem and marital relation improved after educational supportive program. Recommendations: It was recommended that the components of an educational-supportive program should be integrated as a main part of the women' treatment plan provided to women who undergo hysterectomy. Further researches are needed to replicate the study using a larger sample size of women recruited from different geographical areas all over Egypt.
\end{abstract}

Keywords: Hysterectomy, Self-esteem, Marital relation

\section{INTRODUCTION}

Female genital organs (FGO) are very important in determining female sexual identity. For many women, the uterus is the symbol of femininity, sexuality, fertility, motherhood and they feel that their partners will not like them; they lose their attractiveness and they will be unable to fulfill sexual function after surgery. Women are also afraid that their sexual desire will decrease and early aging will follow after the removal of their ovaries (Devi, Sheran \& Sarin, 2015).

Hysterectomy surgery is commonly performed in Gynecology. Moreover, it is one of the commonest operative procedures in the developed world. Hysterectomy is the surgical removal of the uterus (Costantini et al., 2013). It may also involve removal of the cervix, ovaries, fallopian tubes and other surrounding structures. The types of hysterectomy include total (removal of the cervix) and subtotal 
(supra-cervical removal of the uterus), with or without unilateral or bilateral oophorectomy (Darwish, Atlantis \& Mohamed-Taysir, 2014). Previous studies have reported that more than half of all hysterectomies are carried out because of abnormal uterine bleeding, which is associated with a wide range of diagnoses that include uterine fibroids, endometriosis, adenomyosis, and dysfunctional uterine bleeding (Briedite et al., 2014). More than 600,000 hysterectomies in the United States and around 140,000 in Germany hysterectomies are performed each year (Butt, Jeffery \& Van der Spuy, 2012). The National Center for Health Statistics reports that the annual incidence rate for hysterectomies was 165 per 100,000 (Marta et al., 2015 \& Egypt Demographic and Health Survey, 2014).

Hysterectomy surgery has both physical and biologic side effects, such as disruption of body integrity and loss of fertility and also cause psychosexual and social problems such as loss of the love of others and feminine features. In addition, psychological morbidity (as depression, anxiety, and stress-related symptoms), could be triggered by negative perceptions about body image, femininity, youth, energy and activity levels, as well as loss of child-bearing capacity. Also, the study mentioned that $82 \%$ of hysterectomy patients reported a poor body-image which may be attributed to the importance attached to this organ (Fram, Saleh \& Sumrein, 2013). Most of the women perceive the uterus as an incubator to carry babies and believe that it is a symbol of their fertility. These changes may, in turn, influence sexual functioning. For example, many women believe that the best period of their lives will come to an end following hysterectomy and view the surgery as the loss of youth, femininity, and health. Hysterectomy may also result in the development of new problems as: pelvic / abdominal pain, urinary problems, constipation, weight gain, fatigue, and lack of interest or enjoyment in sex, depression, anxiety and negative feelings about oneself as a woman (Sparic et al., 2011).

Studies reveal that most of the women who have experienced hysterectomy surgery are concerned about the change in their sexual situation and being rejected by their husbands. It diminishes their sexual desire also. Thereby it causes rejection on behalf of their husbands as it increases the couples' problems (Shirinkam et al., 2011). After hysterectomy women experience depression with lowered self-esteem. The loss of the uterus and the real or symbolic child bearing ability following hysterectomy has been historically associated with reduced sexual functioning (Danesh et al., 2015).

Marital adjustment requires an acceptance between the couple to the extent where there is the presence of companionship between the two, agreement on the need for affection and intimacy and also accommodation which the couple provides each other (Avci \& Kumcagiz, 2011). One of the major reasons which disturb the pattern of marital adjustment between a husband and a wife is due to the changes brought about by the gynecological disorders which have both physical as well as psychological impact (Pandey et al., 2014).

Social support plays a crucial role in coping. However, a more recent study found that women have reported greater interaction with family and friends after hysterectomies because of an increased desire for socialization and improved energy levels. Positive support can build a person's self-esteem, confidence, and coping abilities especially if this support comes from the partner, whereas negative support coping more difficult. Women coping abilities further require the support of health staff member; mostly of nurses. They play a central role in providing care and health awareness to women after surgery and preventing and/or reducing complications during or after surgery. Playing the roles of educators, nurses also teach women undergoing hysterectomy to overcome their negative thought and feeling (Yaman \& Ayaz, 2015). Women who were provided with information regarding conditions they may experience after hysterectomy and discharge were reported to feel better and experience the higher quality of life than women who did not receive such information. The importance of health education services preoperatively at discharge and postoperatively has been recognized and this service should be provided by expert nurses Rannestad et al., 2001.

\section{Significance of the study}

During the last year, the incidence of hysterectomy increased among gynecological operations to reach 350 cases, according to the annual statistics of Fayoum University hospital. In Egypt, the annual incidence rate for hysterectomy was 165 per 100,000 hysterectomies are performed each year according to the National Center for Health Statistics (Egypt Demographic and Health Survey, 2014). More than 600,000 in the United States and around 140,000 in Germany hysterectomies are conducted each year (Marta et al., 2015). 
Hysterectomy constitutes a noteworthy surgical method and it has a negative effect on women' life as well as women' family. Women with hysterectomy endure the combination of physical, psychological and social issues that influence adversely on numerous part of their life as mental self-esteem, sexuality and marital relation.

A post- hysterectomy woman who cannot adapt to her new condition may not feel great when dealing with her husband because she lost her feeling of femininity which can affect negatively on her self-esteem, sexual life and martial stability. An educational, supportive and adaptive program is meant to be a helping approach for those women who experienced hysterectomy. It highlights the emotional and intellectual experiences of a woman, how she feels and thinks about her life post hysterectomy. Since support is an imperative nursing part, the nurse ought to know about the needs and sentiments of women after hysterectomy to help them to cope with her present condition and enhance their life. Moreover, nurses can help to allay fear and anxiety, as well as dismantle old beliefs about hysterectomy that negatively affects mood and sexual functioning. Heath educator as a team member of the health care providers can better prepare women who undergo hysterectomy and provide them more realistic expectations. The present study will contribute to a greater understanding of the impact of an educational-supportive program on self-esteem level and the marital relation among women undergone hysterectomy especially a few research studies were found examined the utilization of an educational, supportive program on Egyptian women undergone hysterectomy.

\section{Aim of the Study}

The aim of the current study was to study the effect of the educational-supportive program on the self-esteem and the marital relation among women undergone the hysterectomy.

\section{This aim will be achieved through}

(1) By constructing an educational-supportive program to help women undergoing hysterectomy to overcome the negative impact of the surgery.

(2) By studying the effect of an educational-supportive program on self-esteem and the marital relation among women undergone a hysterectomy.

\section{Research Hypotheses}

(1) Women with hysterectomy who received an educational-supportive program would have improvement in their self-esteem than before the program.

(2) Women who received an educational-supportive program after hysterectomy will exhibit an improvement in their marital relation.

\section{RESERCH METHODOLOGY}

Research Design: A quasi-experimental Pretestposttest design was utilized in this study.This design is one type of the quasi-experimental designs in which data was collected from research subjects both before and after introducing the intervention(Nieswiadomy, 2011).

Study Setting: The study was conducted at gynecological outpatient clinic in Fayoum University hospital. The current study program was conducted in the hospital's lecture room, which can accommodate for 15 individuals at once.

Sample: A purposive sample was utilized in this study. A total of (60) participants were selected according to the following statistical formula $n=\mathrm{Z} 2 \mathrm{p}$ (1$p) / \mathrm{d} 2$, where $z=$ level of confidence according to the standard normal distribution (for a level of confidence of $95 \%, z=1.96) . p=$ estimated proportion of the population that presents the characteristic (when unknown we use $p=0.5), d=(d$ is considered 0.05).

All women who participated in the study were selected according to the following inclusion criteria; age within reproductive years (15-49), married women live with their husbands, who had undergone hysterectomy; complaint from sexual dysfunction, traditional family types; free from any chronic disease and underwent successful hysterectomy within the last 6 months that considered as a recovery period. Exactly during this time women may not have a complete image of what happened to her. In addition, after six months the woman already knows the problems (challenges) which affect her life after hysterectomy and maybe adapting negatively. Excluded criteria from this study were women with mental/physical illness. 


\section{Tools for data collection}

Five tools were used by the researchers to collect data:

\section{A. Women Structured Interviewing Questionnaire:}

This tool was developed in simple Arabic language and used by the researchers after extensive literature review. It includes questions related to 1) Sociodemographic characteristics as: age, educational level, occupation, place of residence, duration of marriage, monthly income, having children and reason of hysterectomy.

\section{B. Health Assessment Questionnaire:}

This tool was developed in simple Arabic language and used by the researchers after an extensive literature review and it consists of three parts:

Part I: Contained questions asking on women' received counseling and instructions after hysterectomy and is the source of these instructions is.

Part II: Contained questions related to assessment of women complain after a hysterectomy including sexual, psychological and physical complaints.

Part III: Contained questions related to assessment of the perceived sexual issues before and after hysterectomy: this part asks about the perceived sexual issue before and after hysterectomy as; a-maintaining sexual relation, change in sexual relation after hysterectomy and causes of this change, as well as the frequency of sexual activity. The reliability was estimated by the Cronbach's alpha; value was 0.79 .

C. Rosenberg Self-Esteem Scale: It was adopted by a widely used self-report instrument for evaluating individual self-esteem (Rosenberg, 2016). The questionnaire consists of ten questions. The questions were presented in the form of statements that are answered by the women on the basis of a 4-point Likert scale ranging from (strongly agree $=1$ ) to (Strongly Disagree $=4$ ). Conversely items 2, 5, 6, 8, 9 are reversely scored. Give "Strongly Disagree" 1 point, "Disagree" 2 points, "Agree" 3 points, and "Strongly Agree" 4 points. Higher scores indicate higher selfesteem. This tool translated into the simple Arabic language by the researchers. In this study, the reliability was estimated by the Cronbach's alpha; value was 0.91 .

D. Marital Relations Questionnaire: It consists of two parts;

\section{Part I}

It was developed by the researchers in simple Arabic language after studying different scientific resources and related literature on the marital relation of women that had the hysterectomy. It is a multidimensional measure that consists of 25 items in a statement form, with a three-point rating scale. ( 3 for strongly agree, 2 for somewhat agree and 1 for disagree). The tool covers two main domains of marital relation; marital adjustment (13 questions); and marital intimacy (12 questions). Higher scores in each subscale are indicative of good condition and the higher scores in the overall summation of the scale are indicative of the good marital relationship.

\section{Part II}

The Female Sexual Function Index (FSFI): The researchers used the Arabic version by which translated by Anis et al., (2011) and valid in an Egyptian population. It is a brief, 19-item self-report measure of female sexual function that provides scores on six domains of sexual function as well as a total score. It includes: desire ( 2 items), arousal (4 items), lubrication (4 items), orgasm (3 items), satisfaction (3 items), and pain ( 3 items). Responses to each question relate to the previous month and are scored either from 0 (no sexual activity) or 1 (suggestive of dysfunction) to 5 (suggestive of normal sexual activity). The minimum score possible is 2 and the maximum is 36 . The cut-off score used to demarcate sexual dysfunction on the total FSFI score was obtained from a validation study and determined a total score below 26.55 to denote sexual dysfunction. The cut off scores to determine the presence of difficulties on the six domains of the FSFI were obtained from published sources; accordingly scores less than 4.28 on the desire domain, less than 5.08 on the arousal domain, less than 5.45 on the lubrication domain; less than 5.05 on the orgasm domain; less than 5.04 on the satisfaction domain; and less than 5.51 on the pain domain were used to classify participants as having difficulties in that domain. This tool translated to simple Arabic language by the researchers. In this study, the reliability was estimated by the Cronbach's alpha; value was 0.89 .

E. Spousal Support Scale: It was adopted by Yildirim (2004). It consists of 13-items, five-point Likert- scale (one strongly disagree to five strongly agree) designed 
to measure spousal support behavior for women with hysterectomies. The scoring system is the following Low spousal support $(<21.5)$, Moderate spousal support (21.5- <43), High spousal support (43-65). The scores range from 13 to 65 and high total scores indicate a higher level of support from the spouse. This tool translated to simple Arabic language by the researchers, in this study, the reliability was estimated by the Cronbach's alpha; value was 0.80 .

Validity and Reliability of the Tool: The content validity of these questionnaires was revised by three experts in the field of Maternal and Neonatal Health Nursing and community health nursing, and there were minor identified modifications. Cronbach alpha coefficients were calculated to examine the measurement reliability with multipoint items. All the tools were proven reliable as mentioned in each tool.

Pilot Study: A total of $10 \%$ of the study sample was included in the pilot study in order to assess the feasibility of the study, accessibility of the sample and clarity of the tools, as well as determine the time needed to answer the questions. Minor modifications were needed and women who were participated in the pilot research excluded from the main sample of study.

Ethical Considerations: Official permission was granted from the director of Fayoum University Hospital. The researchers introduced themselves to women who met the inclusion criteria and informed them about the purpose of this study to obtain their acceptance for participation. The researchers assured the woman that the study posed no risk or hazards to them. All women were informed that participation in the study is voluntary and anyone can withdraw anytime without giving any reason, and anonymity and confidentiality were assured. Oral consent was taken from the participants who agreed to participate.

Procedure: Recruitment and follow-up of participants were carried out from June, 2017 to April, 2018. The researchers attended in the pre-determined hospital interchangeably as three days per week starting at 9.00 a.m. to 2.00 p.m. Before the study got conducted, oral permission was obtained from the women in the study.

Data collection was carried out in three phases: 1) Assessment; 2) Implementation and 3) Evaluation phase.
The questionnaires were administered at three points in time: Baseline (prior to intervention), after one month and then three months of completing the intervention.

Assessment phase: The aim of this phase was to collect baseline women' data through using the women structured interviewing questionnaire as well as to determine their individualized educational needs and design a suitable educational-supportive sessions. Researchers introduce themselves to the women who met the inclusion criteria and agreed to participate in the study.

Health assessment sheet, self-esteem questionnaire, marital relation questionnaire and Spousal Support Scale were filled before implementing the intervention part. Each participant was structurally interviewed for 40-60 minutes. Based on analysis of the previously filled questionnaires, researchers prepared the needed information in a form of illustrated pamphlets with simple Arabic explanations provided to the women and their spouses who attended with them accidently. Trustful and helping relationship, rapport and feeling of warmth are established among researchers and participants to assure confidentiality and encourage them to discuss openly and share their own needs and concerns.

Implementation phase: In this phase, each woman attends three sessions either in a group or individually. It took place at the lecture hall of the hospital, each session lasts one hour and half. According to the previously stated follow-up schedule, three to five women attend each session. Based on participants' preferences, privacy issues and topic of sexual relation will be addressed in the session. Some women preferred to attend the session individually to discuss openly their own issues. Simultaneously husbands who accompanied their wives accidently are invited to attend a separated session to avoid one partner influencing the other. The researchers followed up with women by the telephone to determine the suitable time for them. Utilizing different teaching methods such as lectures, discussions, videos and role play, the following topics were discussed in the first two sessions: sexual function, physiology of sexual response in men and women, societal myths related to sexuality after hysterectomy, discussing interpersonal conflicts, the importance of emotional support, the researchers 
taught the women how to cope with their change, and how to overcome their negative thoughts. Additionally, the researchers taught the women how to set the mood for marital intimacy, use of new sexual games and positions and change their sexual routines, using relaxation techniques, the role of love and sexual relationship and how to improve women's self-esteem, eat a healthy diet and get regular exercise as Kegel exercise.

Before each session, the researcher gave time to women to express their own feelings and then there was the discussion on the predetermined topics. At the end of each session the researchers made the conclusion and took feedback. The researchers mentioned that women have to feel free to call them during specific determined one hour daily (researchers set one afternoon hour/day for participants to call them for any further discussion they need either to call or through chatting via mobile communication programs). In the third session "Wrap Up", the researchers summarized all the information and techniques taught and took feedback from each participant. During this phase, four participants were dropped out because of health condition and personal circumstances from the sample subjects and successfully they were replaced.

Evaluation phase: Each woman was evaluated twice after the implementation of the educationalsupportive program, (post 1 and post 2) at (one month after implementing the program and three months after post 1 evaluation). Each participant was structurally interviewed for 30-40 minutes to refill the previously stated questionnaire.

\section{Statistical Analysis}

Data entry and statistical analysis were done using the Statistical Package for Social Science (SPSS) version 22 statistical software package. Results were presented as frequencies and percentages. Repeated measures analysis was utilized to test the effectiveness of the intervention between pre and post. Statistical significance was considered at $p$-value $<0.05$.

\section{RESULTS}

The study sample included 60 women with hysterectomy from Fayoum University hospital, at 2017-2018. The mean age was $42.8 \pm 11.3$ years old. Table (1a) shows that slightly more than one-fifth of the participants are able to read and write or have secondary level of education (38.3\% and $35 \%$ respectively).

Table 1a: Socio-demographic characteristics of the studied women

\begin{tabular}{|c|c|c|}
\hline \multirow[t]{2}{*}{ Variables } & \multicolumn{2}{|c|}{$N=60$} \\
\hline & No & $\%$ \\
\hline \multicolumn{3}{|l|}{ Age ( completed year) } \\
\hline $20=30$ & 9 & 15 \\
\hline $31=40$ & 29 & 48.3 \\
\hline $41=49$ & 22 & 36.7 \\
\hline Women's mean age (years) & \multicolumn{2}{|c|}{$42.8 \pm 11.3$} \\
\hline \multicolumn{3}{|l|}{ Education } \\
\hline Illiterate & 6 & 10 \\
\hline Read and Write & 23 & 38.3 \\
\hline Secondary education & 21 & 35 \\
\hline High education & 10 & 16.7 \\
\hline \multicolumn{3}{|l|}{ Occupation } \\
\hline Housewife & 42 & 70 \\
\hline Office work & 18 & 30 \\
\hline \multicolumn{3}{|l|}{ Residence } \\
\hline Rural & 22 & 36.7 \\
\hline Urban & 38 & 63.3 \\
\hline \multicolumn{3}{|l|}{ Status of residence } \\
\hline Independent house & 49 & 81.7 \\
\hline Family house & 11 & 18.3 \\
\hline \multicolumn{3}{|l|}{ Age of Marriage } \\
\hline$<1-10$ & 7 & 11.6 \\
\hline$>10-20$ & 32 & 53.3 \\
\hline$>20$ & 21 & 35 \\
\hline \multicolumn{2}{|l|}{ Have children } & 16.7 \\
\hline Yes & 50 & 83.3 \\
\hline \multicolumn{3}{|l|}{ Reason of hysterectomy } \\
\hline Abnormal uterine bleeding & 32 & 53.3 \\
\hline Fibroid uterus & 11 & 18.3 \\
\hline Uterine prolapse & 9 & 15 \\
\hline Others & 8 & 13.3 \\
\hline
\end{tabular}

Seventy percent of the participants are housewives (70\%), slightly more than two-third. More than are living in urban area $(63.3 \%)$ in their independent/ separate house $(81.7 \%)$. Abnormal uterine bleeding is the most common cause of hysterectomy $(53.3 \%)$, fibroid $(18.3 \%)$, uterine prolapse $(15 \%)$ and others $(13.3 \%)$ respectively.

Table (1b) revealed that the mean age of the husband was $47.3 \pm 9.4$ years old. About $43.3 \%$ had a secondary educational level. While the remaining participants $5 \%$ cannot read and write. 
Table (1b): Socio-demographic characteristics of the husbands

\begin{tabular}{|c|r|r|}
\hline \multirow{2}{*}{ Variables } & \multicolumn{2}{|c|}{ N= 60 } \\
\cline { 2 - 3 } & No & \% \\
\hline Husband's age(years) & \multicolumn{2}{|c|}{} \\
$20=30$ & 19 & 6.6 \\
$31=40$ & 37 & 61.6 \\
$41=49$ & \multicolumn{2}{|c|}{$47.3 \pm 9.4$} \\
Husband's mean age(years) & 3 & 5 \\
\hline Husband's Education level & 12 & 20 \\
Illiterate & 9 & 15 \\
Read and Write & 26 & 43.3 \\
primary education & 10 & 16.6 \\
Secondary education & \multicolumn{2}{|c|}{} \\
High education & 41 & 68.3 \\
Income & 19 & 31.7 \\
Enough & \multicolumn{2}{|c|}{} \\
Not enough & & \\
\hline
\end{tabular}

Receiving rehabilitation sessions to satisfy their need after hysterectomy, about $30 \%$ were receiving sessions. Most of the participants had instruction after hysterectomy from friends and neighbors, while the remaining are from the internet $6.6 \%$ Table 2 .

Table 2: Distribution of the studied sample in relation to receiving rehabilitation sessions to satisfy her needs after hysterectomy

\begin{tabular}{|c|l|}
\hline Items & $\begin{array}{l}\text { N= 60 } \\
\text { No (\%) }\end{array}$ \\
\hline $\begin{array}{c}\text { Receiving rehabilitation sessions } \\
\text { Yes }\end{array}$ & $18(30)$ \\
No & $42(70)$ \\
\hline$* * * *$ Source of instructions after & \\
hysterectomy & $6(10)$ \\
Doctor & $5(8.3)$ \\
Nurse & $37(61.6)$ \\
Friend and neighbor & $8(13.3)$ \\
Mass media & $4(6.6)$ \\
Internet & \\
\hline ****non-mutual responses
\end{tabular}

Regarding post-hysterectomy complaints, about half of the participants had vaginal dryness, $(81.7 \%)$ had low self-esteem and $(80 \%)$ were unsatisfied body image perception (Table 3 ).
Table 3: Distribution of common post-hysterectomy complaints

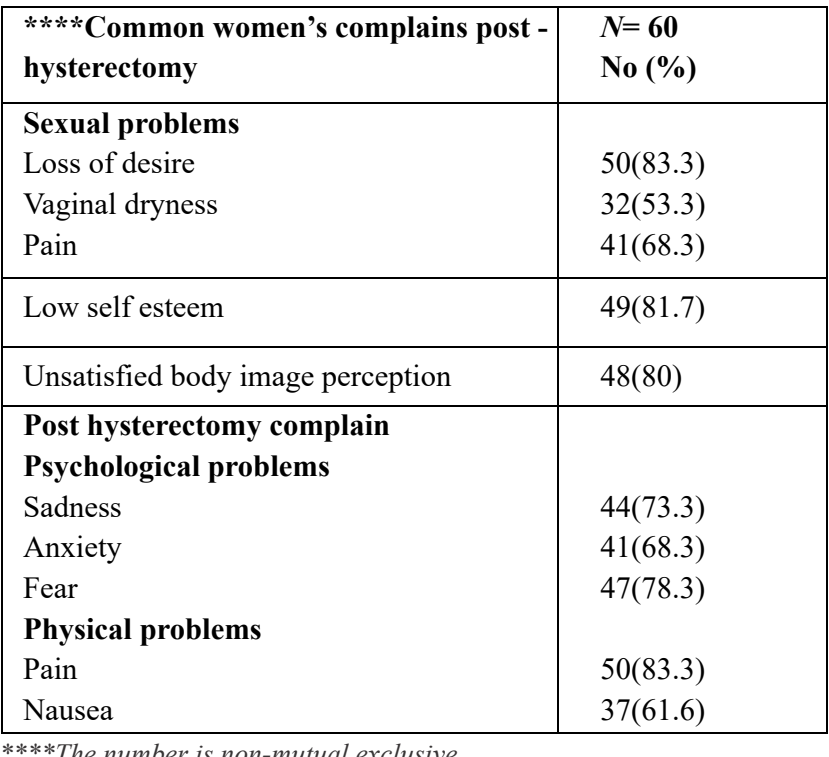

Table 4 shows the change in the sexual relation after hysterectomy $(88.3 \%)$ with statistically significant differences.

Table 4: Distribution of the sample regarding sexual issue before and after as perceived by the women

\begin{tabular}{|c|c|c|c|}
\hline \multirow[t]{2}{*}{ Items } & \multicolumn{2}{|c|}{$N=60(\%)$} & \multirow[t]{2}{*}{$p$-value } \\
\hline & \begin{tabular}{|c|} 
Before \\
hysterectomy
\end{tabular} & $\begin{array}{c}\text { After } \\
\text { hysterectomy }\end{array}$ & \\
\hline $\begin{array}{l}\text { Present of sexual relation } \\
\text { Yes } \\
\text { No }\end{array}$ & $\begin{array}{c}60(100) \\
0(0)\end{array}$ & $\begin{array}{c}60(100) \\
0(0)\end{array}$ & -- \\
\hline $\begin{array}{l}\text { Physical status of the husband } \\
\text { Healthy } \\
\text { Not healthy }\end{array}$ & $\begin{array}{c}52(86.7) \\
(13.3) 8\end{array}$ & $\begin{array}{c}52(86.7) \\
(13.3) 8\end{array}$ & -- \\
\hline $\begin{array}{c}\text { Change in the sexual relation } \\
\text { Yes } \\
\text { No }\end{array}$ & $\begin{array}{l}12(20) \\
48(80)\end{array}$ & $\begin{array}{c}53(88.3) \\
7(11.7)\end{array}$ & $0.001 *$ \\
\hline $\begin{array}{l}\text { Causes of change in sexual } \\
\text { relation after hysterectomy } \\
\text { due to: } \boldsymbol{n}=\mathbf{5 3} \\
\text { hysterectomy } \\
\text { Other causes }\end{array}$ & - & $\begin{array}{c}48(90.6) \\
5(9.4)\end{array}$ & -- \\
\hline $\begin{array}{l}\text { Person responsible for change } \\
\text { in sexual relation after } \\
\text { hysterectomy: } \boldsymbol{n}=\mathbf{5 3} \\
\text { Woman } \\
\text { Husband }\end{array}$ & - & $\begin{array}{c}47(88.7) \\
6(11.3)\end{array}$ & -- \\
\hline
\end{tabular}


Regarding self-esteem and sexual function scores, the score of self-esteem was high after three and six months with statistically significant differences. While the total sexual functions score was improved after three and six months with statistically significant differences (table 5)

Table 5: Distribution of the Sample According to women's self-esteem and Sexual Function Scores

\begin{tabular}{|l|r|r|r|l|}
\hline \multirow{2}{*}{ Variable } & $\begin{array}{r}\text { Before } \\
\text { intervention }\end{array}$ & $\begin{array}{l}\text { One } \\
\text { months } \\
\text { later }\end{array}$ & $\begin{array}{l}\text { Three } \\
\text { months } \\
\text { later }\end{array}$ & P-value \\
\cline { 2 - 5 } & \multicolumn{5}{|c|}{ Mean(SD) } \\
\hline Self esteem & $14.09(1.3)$ & $23.82(2.1)$ & $24.9(1.5)$ & $<0.001$ \\
\hline & \multicolumn{5}{|c|}{ Sexual Function Scores } \\
\hline Desire & $3.5 \pm 0.4$ & $6.9 \pm 0.9$ & $12.4 \pm 0.5$ & $<0.001$ \\
\hline Arousal & $2.1 \pm 0.6$ & $2.7 \pm 0.8$ & $3.5 \pm 0.7$ & $<0.001$ \\
\hline Lubrication & $2.0 \pm 0.3$ & $2.9 \pm 0.8$ & $3.2 \pm 0.9$ & $<0.001$ \\
\hline Orgasm & $1.03 \pm 0.2$ & $2.5 \pm 0.7$ & $3.3 \pm 0.9$ & $<0.001$ \\
\hline Satisfaction & $2.01 \pm 0.5$ & $2.5 \pm 0.8$ & $3.1 \pm 0.7$ & $<0.001$ \\
\hline Pain & $4.9 \pm 0.6$ & $3.8 \pm 0.5$ & $3.1 \pm 0.7$ & $<0.001$ \\
\hline Total score & $\mathbf{1 5 . 5 4} \pm \mathbf{2 . 6}$ & $\mathbf{2 1 . 3} \pm \mathbf{4 . 5}$ & $\mathbf{2 8 . 6} \pm \mathbf{4 . 4}$ & $<\mathbf{0 . 0 0 1}$ \\
\hline
\end{tabular}

Concerning martial relations, the total score was improved at three and six months with statistically significant differences (Table 6).

Table 6: Marital relation scores among the studied sample at differentperiod of the intervention

\begin{tabular}{|l|l|l|l|l|l|}
\hline Variables & $\begin{array}{l}\text { Before } \\
\text { intervention }\end{array}$ & $\begin{array}{l}\text { One } \\
\text { months } \\
\text { later }\end{array}$ & $\begin{array}{l}\text { Three } \\
\text { months } \\
\text { later }\end{array}$ & $\boldsymbol{F}$ & $\begin{array}{l}\boldsymbol{p} \text { - } \\
\text { value }\end{array}$ \\
\cline { 2 - 6 } & Mean(SD) & & \\
\hline $\begin{array}{l}\text { Marital } \\
\text { intimacy }\end{array}$ & $18.10(6.5)$ & $23(4.2)$ & $26.11(5.6)$ & 13.7 & $0.002 *$ \\
\hline $\begin{array}{l}\text { Marital } \\
\text { adjustment }\end{array}$ & $25.02(2.3)$ & $30.11(1.4)$ & $32(3.4)$ & 8.5 & $0.000^{*}$ \\
\hline Total Score & $45.06(9.6)$ & $55.52(11)$ & $61.12(15.2)$ & 9.3 & $0.002 *$ \\
\hline signifiant $<0.05$ & &
\end{tabular}

Regarding spousal support after hysterectomy, there was a moderate spousal support with statistically significant differences (table 7).
Table 7: Distribution of the studied Sample According to their Spousal Support after hysterectomy at different times of intervention

\begin{tabular}{|c|c|c|c|c|c|}
\hline \multirow[t]{2}{*}{ Spousal support } & \begin{tabular}{|c|}
$\begin{array}{c}\text { Before } \\
\text { intervention }\end{array}$ \\
\end{tabular} & \begin{tabular}{|l|}
$\begin{array}{l}\text { One } \\
\text { months } \\
\text { later }\end{array}$ \\
\end{tabular} & \begin{tabular}{|l|} 
Three \\
months \\
later
\end{tabular} & \multirow{2}{*}{$F$} & \multirow[t]{2}{*}{$P$-value } \\
\hline & \multicolumn{3}{|c|}{$N(\%)=60$} & & \\
\hline $\operatorname{Low}(<21.5)$ & $36(60)$ & $24(40)$ & $20(33.3)$ & 14.5 & 0.05 \\
\hline Moderate $(21.5-<43)$ & $19(31.6)$ & $28(46.6)$ & $31(51.6)$ & 9.8 & 0.03 \\
\hline $\operatorname{High}(43-65)$ & $5(8.3)$ & $8(13.3)$ & $9(15)$ & 10.2 & 0.05 \\
\hline
\end{tabular}

Table 8 shows that the spousal support has statistically positive significant relation with women's self-esteem, sexual function and the marital relations in different periods of time; before one month later and three months later.

Table 8: Correlation coefficient between total spousal support and women's' self-esteem, sexual function and marital relations of different times of the program

\begin{tabular}{|l|l|l|l|}
\hline \multirow{2}{*}{ Variable } & \multicolumn{3}{|c|}{ Total spousal support } \\
\cline { 2 - 4 } & $\begin{array}{l}\text { Before } \\
\text { intervention }\end{array}$ & $\begin{array}{l}\text { One months } \\
\text { later }\end{array}$ & $\begin{array}{l}\text { Three months } \\
\text { later }\end{array}$ \\
\cline { 2 - 4 } & \multicolumn{3}{|c|}{$r(p)$} \\
\hline Total self esteem & $0.682(0.03)$ & $0.897(0.001)$ & $0.895(0.04)$ \\
\hline $\begin{array}{l}\text { Total sexual } \\
\text { function }\end{array}$ & $0.587(0.002)$ & $0.874(0.002)$ & $0.056(0.003)$ \\
\hline $\begin{array}{l}\text { Total marital } \\
\text { relation }\end{array}$ & $0.0741(0.04)$ & $0.724(0.001)$ & $0.447(0.04)$ \\
\hline
\end{tabular}

\section{DISCUSSION}

Hysterectomy is the major gynecologic operation that has a resilient effect on the health of women. It is associated with affecting their psychological states and restricting their daily activities negatively (Elweley \& Sabra, 2015). The present study was carried out to assess the effect of an educational-supportive program on self-esteem and marital relations among women undergoing the hysterectomy. Findings of the current study are discussed within the following frame: (1) Socio-demographic characteristics of the participants, and (2) research hypothesis.

Concerning the socio-demographic characteristics of the participants, the present study revealed that about 
half of the women were of age between 31-40 years, while slightly more than half of the woman had husbands, whose ages ranged between 41-49 years. These results in the same line with Selcuk et al., (2016) who reported that around $42 \%$ of all hysterectomy cases are diagnosed in women less than 40 of age, $22 \%$ in women less than 35 years. If plotted on a curve, the cumulative incidence of hysterectomy seems to follow an exponential function below the age of 40 after which it seems to rise linearly. These results are in the same line with Sehlo \& Ramadani (2010) who stated that younger women are more at risk for psychiatric disorder after hysterectomy.

Regarding the educational level and residence of the participants, more than one-third of the participants in the present study were literate and had the secondary level of education and they were living in urban areas. This results in the same line with Elmoneim, Ghonemy \& Hassan (2017) who stated that more than one-third of the women undergoing the hysterectomy in their study were literate and live in rural areas.

The current study revealed that more than two-thirds of the sample did not receive rehabilitation sessions after hysterectomy. In addition, slightly less than two-thirds of the sample obtained the post- hysterectomy instructions from friends and neighbor only. This finding may be attributed to the fact that there is lack of the counseling or rehabilitation program after the surgery and this is the neglected area in the Egyptian community; and it was noticed that the health care providers are only concerned with the success of the surgical operation, not with the psychological consequences of it. This result corresponds with Enien et al., (2018) who did a study to investigate the quality of life among women who underwent radical mastectomy and found that, the source of instructions among the studied post-surgical group was $66.7 \%$ \& $17.3 \%$ from their friends, neighbor and mass media respectively.

Regarding the post-hysterectomy complaints of the most common women, the current results showed that sexual problems especially the loss of desire was most reported by the maximum of the sample and it was followed by low self-esteem and unsatisfied body image perception. More than two-thirds of the participants complained about the psychological problem like sadness, anxiety, and fear. In addition, most of the women in the current study reported that their sexual relations changed after hysterectomy. It may be that women consider the uterus as the source of their femininity and continuity of her reproductive life. Thus if she loses it, she will lose her identity and desire to have sex.

This result is similar with Arroyo \& Lopez (2011) who conducted the qualitative study about problems derived from the hysterectomy. This qualitative study found that most common problems the women face after hysterectomy were sexual problems (losing the desire and reduced frequency) and low self-esteem that resembles about more than three-fourths of the sample. In addition, the previous results were also supported by Dessources et al., (2015) who found that $70 \%$ of women after hysterectomy face sexual function problems within a few months after surgery. About $83 \%$ of the women in the study considered their sex life good and satisfying before hysterectomy, but noticed a real decline after they underwent treatment.

The previous results are also supported by Elweley \& Sabra (2015) who studied the Psychological problems, concerns and beliefs in women undergoing hysterectomy, as he found that $58 \%$ of the studied participants exhibiting anxiety symptoms (46\% and $12 \%)$ had moderate and severe anxiety respectively. The findings also revealed that Femininity and sexual attractiveness were the prime concerns for the women for 8 weeks after hysterectomy as presented by $(80,00 ; 88,00)$ respectively. The current results agree with Patil et al., 2017; Bradford \& Meston, 2007) whose study correlates of anxiety in patients scheduled for hysterectomy and found that the participants had the moderate mean score on anxiety, depressed mood, fears, genitourinary and intellectual symptoms after hysterectomy surgery.

The First Hypothesis: Women with hysterectomy who received an educational-supportive program would have improved in their self-esteem than before the program. In the present study, there was an improvement with the highly significant difference in the mean selfesteem scores among the women undergoing hysterectomy from before, one month later and three months later of intervention. This may be due to the fact that the woman considers the breast as the main source of femininity which helps her to feel like the female and increases her self-confidence in front of her husband and 
herself. During the intervention sessions, the researchers helped the women to overcome this feeling and restore her confidence as well as increase her self-esteem.

The present study findings were congruent with the study conducted by Darwish, Atlantis \& Mohammed (2014) who studied the effect of hysterectomy on the lives of women. He found a relationship between selfesteem and hysterectomy; there was low self-esteem arisen from a negative thought in some women after hysterectomy and this can be improved by supportive educational/rehabilitation. While the current results contradicted by Hehenkamp et al., (2007) who studied the effect of hysterectomy on self-esteem. He found that there were similar pre- and post-test self-esteem and body image scores among the patients in the intervention group after educational session.

In addition, the previous results contradict with Darwish, Atlantis \& Mohammed (2014) as they concluded that hysterectomy for benign gynecological conditions is not adversely associated with anxiety and may be positively associated with depression. Helmy et al., (2008) studied the effect of education for the women after hysterectomy revealed that the educational session cannot improve the feeling of low self-esteem and low body-image perceived among the women after hysterectomy.

The Second Hypothesis: Women who receive educational-supportive program after hysterectomy exhibit an improvement in their marital relations. In the present study, in the post-hysterectomy phase most of the women in the present study suffer from sexual problems like loss of desire $(83.3 \%)$, vaginal dryness $(53.3 \%)$, and pain $(68.3 \%)$. The result also revealed that there was a highly statistical difference between the mean score of subgroup (Desire, Arousal, Lubrication, Orgasm, Satisfaction and pain) and the total mean score of sexual function scores before, one month later and three months later after the implementation of the supportive program for the studied sample. In addition, the subgroup for marital relation (marital intimacy and marital adjustment) as well as the total score of martial relation were improved at different periods of time (one month and three months later) after the intervention with high statistical significant differences. This may be related to the fact that after hysterectomy there is the decrease in sensation of the vagina, dyspareunia (painful intercourse), loss of vaginal elasticity and lubrication. The removal of the ovaries causes a sudden loss of estrogen and androgen production which can affect sexual responses. The age of the studied sample was also an influencing factor to the improvement of their sexual and marital relationships because they seek any methods to save their marital lives. From this point she obeys any instruction to take the session and tries to apply it.

In this respect the previous finding was consistent with Clark et al., (2001) who reported that after the reframing program for women undergoing hysterectomy, changes within the experimental group were more positive than those who were in the control group regarding the sexual function and marital intimacy score among post-hysterectomy women. As well as several studies that have suggested that interventions of women are beneficial for promoting empathic communication and better marital adjustment after hysterectomy (Sloan, 1978; Gibson et al., 2013; Hashim et al., 2010) These findings are also congruent with Priya et al., (2014) who reported that the sexual satisfaction was negative among post-mastectomy women. The rehabilitation program helps the women to manage her thinking during sexuality; there was a statically significant difference between the cognitive distraction during sexual activity and sexual satisfaction score pre and after the program.

Regarding the spousal support of women, the current result pointed to the fact that there was improvement in the level of spousal support to their women who underwent the hysterectomy after the implementation of the supportive program with a statistically significant difference. From this point, the current result also exhibits that the spousal support has positive and statistically significant relation with selfesteem of women, sexual function, and marital relation in the different period of time before, one month later and three months later. This may be due to the fact that the source of psychological disturbance of women after the hysterectomy is her husband as she is afraid to lose her husband and deterioration of the marital relation. But when the women get support from her husband, at this time she has the ability to cope with the situation and overcome all negative thought and vice versa.

The previous result in the same line with Elmoneim, 
Ghonemy \& Hassan (2017) who reported that the spousal support for their women with hysterectomy show marked group different (within the study group) pre-education than post education as $\left(\mathrm{T} 1=6.9^{*} P<0.01\right)$, as well as marked significant differences between the study \& control group as $\left(\mathrm{T} 4=2.4 P<0.05^{*}\right)$. They also added that these positive relations between spousal support and hysterectomy beliefs and intention among Egyptian women are important. Present results showed that women who perceived higher spousal support had more positive beliefs towards their hysterectomy including perceived higher benefits, lower barriers, and higher norms. Marván, Trujillo \& Karam (2009) stated that many women have complicated feelings after hysterectomy, specifically about the probability of being unseen as appealing by their spouse, as before the hysterectomy, that their attractiveness as a sexual partner would fade \& their sexual life would be hampered.

\section{CONCLUSION}

The present study concluded that the women after hysterectomy confront many psychological problems such as: negative perceived low self-esteem, low sexual satisfaction and low marital relation satisfaction. The application of the supportive program was also effective in improving the women's self-esteem, and marital relation.

\section{RECOMMENDATION}

In light of the study findings, the following recommendations are suggested:

- Counseling / psychosocial intervention programs should be an integral part of the gynecological treatment; especially those can affect women life as hysterectomy and must be available in all gynecological departments to guide the women with hysterectomy.

- It is important to establish strategies to facilitate the husband's understanding and support to the potential impact of surgery-related hysterectomy on women and integrated into discharge plane.

- In-service education programs for nurses about how to deal with and manage various psychological problems with post-hysterectomy women.

\section{Further Research}

- Replication of the study using a larger sample size of women recruited from different geographical areas all over Egypt.

- Further studies are still needed to determine the effect of different coping strategies on stress level for post-hysterectomy women.

- Further qualitative studies are needed to make elaborate on the women's experience after hysterectomy and its impact on their lives.

\section{REFERENCES}

Anis, T.H., Gheit, S.A., Saied, H. \& Alkhebash, S.A. (2011). Arabic Translation of Female Sexual Function Index and Validation in an Egyptian Population. The Journal of Sexual Medicine, 8(12), pp 3370-3378.

Arroyo, J.M.G \& Lopez, M.L.D. (2011). Psychological Problems Derived from Mastectomy: A Qualitative Study. International Journal of Surgical Oncology, Pages 8.

Avci, I.A. \& Kumcagiz, H. (2011). Marital Adjustment and Loneliness Status of Women with Mastectomy and Husbands Reactions. Asian Pacific Journal of Cancer Prevention, 12(2), pp 453-459.

Bradford, A. \& Meston, C. (2007). Sexual Outcomes and Satisfaction with Hysterectomy: Influence of Patient Education. The journal of Sexual Medicine, 4(1),pp 106-114.

Briedite, I., Ancane, G., Rogovska, I. \& Lietuviete, N. (2014). Quality of Female Sexual Function After Conventional Abdominal Hysterectomy-Three Months' Observation. Acta Chirurgica Latviensis, 14(1), pp 26-31.

Butt, J.L., Jeffery, S.T. \& Van der Spuy, Z.M. (2012). An Audit of Indications and Complications Associated with Elective Hysterectomy at a Public Service Hospital in South Africa. International Journal of Gynecology \& 
Obstetrics, 116(2), pp 112-116.

Clark, J., Daniels, J., Khan, K.S. \& Gupta, J.K. (2001). Hysterectomy with Bilateral Salpingo Oopherectomy: A Survey of Gynecological Practice. Acta Obstetricia Gynecologica Scandinavica, 80(1), pp 62-64.

Costantini, E, Porena M, Lazzeri M, Mearini L, Bini V. \& Zucchi, A. (2013). Changes in Female Sexual Function after Pelvic Organ Prolapse Repair: Role of Hysterectomy. International Urogynecology Journal, 24(9), pp1481-1487.

Danesh, M., Hamzehgardeshi, Z., Moosazadeh, M. \& Shabani-Asrami, F. (2015). The Effect of Hysterectomy on Women's Sexual Function: A Narrative Review. Medical Archives, 69(6), pp 387-392.

Darwish, M., Atlantis, E. \& Mohamed-Taysir, T. (2014). Psychological Outcomes After Hysterectomy for Benign Conditions: A Systematic Review and Meta-Analysis. European Journal of Obstetrics and Gynecology and Reproductive Biology, 174, pp 5-19.

Dessources, K., Hou, J.Y., Tergas, A.L., Burke, W.M., Ananth, C.V., Prendergast, E., Chen, L., Neugut, A.I., Hershman, D.L. \& Wright, J.D. (2015). Factors Associated with 30-day Hospital Readmission after Hysterectomy. Obstetrics \& Gynecology, 125(2), pp 461-470.

Devi, K.N., Sheoran, P. \& Sarin, J. (2015). Effect of Structured Discharge Teaching After Hysterectomy. International Journal of Reproduction, Contraception, Obstetrics and Gynecology, 4(5), pp 1384-1395.

Egypt Demographic and Health Survey (2014).Ministry of Health and Population Cairo, Egypt. Retrieved from: https://dhsprogram.com/pubs/pdf/FR302/FR302.pdf

Elmoneim, E.F.A., Ghonemy, G.E. \& Hassan, N.I. (2017). Effect of Roy Adaptation Model on Sexual Function and Spousal Support among Women after Total Hysterectomy. IOSR Journal of Nursing and Health Science, 6(2), pp 130-140.

Elweley, M.Z. \& Sabra, A.I. (2015). Psychological Problems, Concerns and Beliefs in Women Undergoing Hysterectomy. IOSR Journal of Nursing and Health Science, 4(6), pp 48-57.

Enien, M.A., Ibrahim, N., Makar, W., Darwish, D. \& Gaber, M. (2018). Health-related quality of life: Impact of surgery and treatment modality in breast cancer. Journal of Cancer Research and Therapeutics, 14(5), pp 957-963.

Fram, K.M., Saleh, S.S. \& Sumrein, I.A. (2013). Sexuality after Hysterectomy at University of Jordan Hospital: A Teaching Hospital Experience. Archives of Gynecology Obsteterics, 287(4), pp 703-708.

Gibson, C.J., Thurston, R.C., El Khoudary, S.R., Sutton-Tyrrell, K. \& Matthews, K.A. (2013). Body Mass Index Following Natural Menopause and Hysterectomy with and without Bilateral Oophorectomy. International Journal of Obesity, 37(6), pp 809-813.

Hashim, A.A., Fawzi, M.M., Haitham, M. \& Nelly, R.A. (2010). Prevalence of eating disorders in a sample of rural and urban secondary school-girls in Sharkia, Egypt. Current Psychiatry, 17(4), pp 1-12

Hehenkamp, W.J.K., Volkers, N.A., Bartholomeus, W., Blok, S.D., Birnie, E., Reekers, J.A. \& Ankum, W.M.(2007). Sexuality and Body Image After Uterine Artery Embolization and Hysterectomy in the Treatment of Uterine Fibroids: A Randomized Comparison. Cardio Vascular and Interventional Radiology, 30(5), pp 866875.

Helmy, Y.A., Hassanin, I.M., Elraheem, T.A., Bedaiwy, A.A., Peterson, R.S. \& Bedaiwy, M.A. (2008). Psychiatric Morbidity Following Hysterectomy in Egypt. International Journal of Gynecology \& Obstetrics, 102(1), pp 60-64. 
Marta, H., Szilvia, T., Geza, H., Tamas, H., Jozsef, B. and Janos G. (2015). Quality of Life, Sexual Functions and Urinary Incontinence After Hysterectomy in Hungarian Women. American Journal of Health Research, 3(6), pp 393-398.

Marván, M.L., Trujillo, P. \& Karam, M.A. (2009). Hysterectomy as viewed by Mexican women and men. Sex Roles, 61(9), pp 688-698.

Nieswiadomy, R.M. (2011). Foundations of Nursing Research. $6^{\text {th }}$ Edition, Pearson, UK.

Pandey, D., Sehgal, K., Saxena, A., Hebbar, S., Nambiar, J. \& Bhat, G. (2014). An Audit of Indications, Complications and Justification of Hysterectomies at a Teaching Hospital in India. International journal of reproductive medicine, pages 6 .

Patil, K., Faye, A., Gawande, S., Tadke, R., Bhave, S. \& Kirpekar, V.(2017). Correlates of anxiety in patients posted for hysterectomy. Journal of Medical Sciences, 7(1), pp 40-44

Priya, V., Sebastian ,S.M., Fenn, M.G., Mathew, A. \& Velusamy, S.K. (2014). A Study to Assess Whether Planned Pre-Operative Education Decreases Anxiety and Improves Satisfaction in Patients Undergoing Surgery-A Randomized Controlled Trial. IOSR Journal of Dental and Medical Sciences, 13(12), pp 1-7.

Rannestad, T., Eikeland, O.J., Helland, H. \& Qvarnström, U. (2001). The Quality of Life in Women Suffering from Gynecological Disorders is Improved by Means of Hysterectomy. Absolute and relative differences between pre- and postoperative measures. Acta Obstetricia et Gynecologica Scandinavica, 80(1), pp 46-51.

Rosenberg, M. (2016). Society and the adolescent self-image. Princeton University Press, USA.

Sehlo, M. G.S. \& Ramadani, H. (2010). Depression Following Hysterectomy. Current Psychiatry, 17(2), pp 1-6.

Selcuk, S., Cam, C., Asoglu, M.R., Kucukbas, M., Arinkan, A., Cikman, M. S. \& Karateke, A. (2016).Effect of Simple and Radical Hysterectomy on Quality of Life - Analysis of All Aspects of Pelvic Floor Dysfunction. European Journal of Obstetrics \& Gynecology and Reproductive Biology, 198, pp 84-88.

Shirinkam, F., Jannat-Alipoor, Z., Chavari, R.S. \& Ghaffari, F. (2018). Sexuality After Hysterectomy: A Qualitative Study on Women's Sexual Experience After Hysterectomy. International Journal of Womens Health and Reproduction Sciences, 6(1), pp 27-35.

Sloan, D. (1978). The Emotional and Psychosexual Aspects of Hysterectomy. American Journal of Obstetrics Gynecology, 131(6), pp 598-605.

Sparic, R., Hudelist, G., Berisava, M., Gudovic, A. \& Buzadzic, S. (2011). Hysterectomy Throughout History. Acta Chirurgica Iugoslavica, 58(4), pp 9-14.

Yaman, S. \& Ayaz, S. (2015). The Effect of Education Given Before Surgery on Self-Esteem and Body Image in Women Undergoing Hysterectomy. Turkish Journal of Obsteterics Gynecology, 12(4), pp 211-214.

Yildirim, I. (2004). Development of spousal support scale. Journal of Turkish Psychological Counselling and Guidence, 3(22), pp 19-25. 